\title{
Serum aspartate aminotransferase level and previous histopathological findings enable reduction of protocol liver biopsies after liver transplantation for hepatitis C
}

\author{
Tomohiro Tanaka MD, George Therapondos MD, Nazia Selzner MD PhD, Eberhard L Renner MD, Leslie B Lilly MD
}

T Tanaka, G Therapondos, N Selzner, EL Renner, LB Lilly. Serum aspartate aminotransferase level and previous histopathological findings enable reduction of protocol liver biopsies after liver transplantation for hepatitis C. Can J Gastroenterol 2013;27(3):131-136.

BACKGROUND: Hepatitis C virus (HCV) infection remains the leading indication for liver transplantation (LT) worldwide. Recurrent hepatitis C following LT is universal, and significant fibrosis (SF, Metavir fibrosis stage $\geq 2$ ) apparent on protocol biopsy typically prompts antiviral therapy.

OBJECTIVE: To determine the optimal timing of protocol liver biopsies in this setting.

METHODS: A total of 151 patients who underwent LT related to HCV infection between July 2004 and December 2009 were analyzed retrospectively. Data regarding protocol liver biopsies at six, 12 and 24 months post-LT, conventional laboratory parameters and demographic information were obtained.

RESULTS: The 151 patients included in the present study had significantly lower serum aspartate aminotransferase (AST) levels than the four patients who progressed to receive antiviral treatment for SF before six months post-LT $(\mathrm{P}<0.001)$. AST level, but not alanine aminotransferase level, histological activity or fibrosis stage at the sixmonth biopsy was independently associated with the progression to SF at 12 months $(\mathrm{P}<0.05)$. However, AST level, histological activity and fibrosis stage at the 12 -month biopsy emerged as independent parameters associated with progression to SF at 24 months $(\mathrm{P}<0.05)$.

CONCLUSION: The protocol liver biopsy at six months could be eliminated, especially in patients who consistently exhibit low AST levels. Histological activity, the presence or absence of fibrosis, and AST values at the 12-month biopsy may lead to the decision to defer the protocol biopsy at 24 months or result in earlier introduction of antiviral therapy.

Key Words: AST; HCV; Liver transplantation; Protocol liver biopsy
Le taux sérique d'aspartate aminotransférase et les observations histopathologiques passées permettent de réduire les biopsies hépatiques de protocole après une transplantation hépatique causée par une hépatite $\mathrm{C}$

HISTORIQUE : L'infection par le virus de l'hépatite C (VHC) demeure la principale indication de transplantation hépatique $(\mathrm{TH})$ dans le monde. La récurrence de l'hépatite $\mathrm{C}$ après une $\mathrm{TH}$ est universelle, et une fibrose importante (FI, score Metavir de fibrose $\geq 2$ ) apparente à la biopsie de protocole suscite généralement une antivirothérapie.

OBJECTIF : Déterminer le moment optimal des biopsies hépatiques de protocole dans cette situation.

MÉTHODOLOGIE : Les chercheurs ont procédé à l'analyse rétrospective d'un total de 151 patients qui avaient subi une TH liée à une infection par le VHC entre juillet 2004 et décembre 2009. Ils ont obtenu les protocoles de biopsie hépatique six, 12 et 24 mois après la $\mathrm{TH}$, ainsi que les paramètres de laboratoire traditionnels et les renseignements démographiques.

RÉSULTATS : Les 151 patients qui ont participé à la présente étude présentaient un taux sérique d'aspartate aminotransférase (AST) considérablement plus faible que celui des quatre patients qui ont dû recevoir une antivirothérapie pour traiter une FI moins de six mois après la TH $(\mathrm{P}<0,001)$. Le taux d'AST, mais pas celui d'alanine aminotransférase, l'activité histologique ou le score de fibrose au moment de la biopsie au bout de six mois s'associait de manière indépendante à l'évolution vers une FI au bout de 12 mois $(\mathrm{P}<0,05)$. Cependant, le taux d'AST, l'activité histologique et le score de fibrose lors de la biopsie de 12 mois se révélaient des paramètres indépendants associés à l'évolution vers une FI au bout de 24 mois $(\mathrm{P}<0,05)$.

CONCLUSION : On pourrait laisser tomber la biopsie hépatique du protocole au bout de six mois, notamment chez les patients qui ont toujours un faible taux d'AST. L'activité histologique, la présence ou l'absence de fibrose et les valeurs d'AST lors de la biopsie de 12 mois pourraient inciter à reporter la biopsie du protocole à 24 mois ou amorcer l'antivirothérapie plus rapidement.

undergo LT for hepatitis $\mathrm{C}$ to monitor disease progression and to determine when to start antiviral treatment. However, liver biopsy is a costly, invasive procedure associated with discomfort, major complications in $0.5 \%$ of patients and even death (6-8). In addition, there is no consensus agreement regarding the optimal timing of protocol liver biopsy.

We conducted the present retrospective study to optimize the timing of protocol liver biopsies post-LT for recurrent hepatitis C by evaluating the predictive value of protocol liver biopsy and conventional laboratory/demographic parameters on progression of graft fibrosis, especially early post-transplant.

\section{METHODS}

The present study was approved by the Research Ethics Board of the University Health Network, Toronto, Ontario (\#11-0558-AE). 


\begin{tabular}{|c|c|}
\hline \multicolumn{2}{|l|}{ Recipient demographics } \\
\hline Recipient age, years, median (range) & $54(36-68)$ \\
\hline Male sex & $129(85)$ \\
\hline \multicolumn{2}{|l|}{ Race } \\
\hline Caucasian & $115(76)$ \\
\hline Asian & $23(17)$ \\
\hline Other & $13(9)$ \\
\hline Body mass index, kg/m², median (range) & $27(17-41)$ \\
\hline \multicolumn{2}{|l|}{ Hepatitis C genotype } \\
\hline 1 & $100(66)$ \\
\hline 2 & $5(3)$ \\
\hline 3 & $33(22)$ \\
\hline 4 & $7(5)$ \\
\hline Nontypable & $6(4)$ \\
\hline MELD score at liver transplant, median (range) & $17(6-40)$ \\
\hline Hepatocellular carcinoma & $85(56)$ \\
\hline \multicolumn{2}{|l|}{ Activity grade of explanted liver } \\
\hline 0 & $1(1)$ \\
\hline 1 & $115(76)$ \\
\hline 2 & $28(19)$ \\
\hline NA & $6(4)$ \\
\hline \multicolumn{2}{|l|}{ Liver transplant-related parameters } \\
\hline Donor age, years, median (range) & $46(11-84)$ \\
\hline Cold ischemia time, min, median (range) & $225(14-1081)$ \\
\hline Warm ischemia time, min, median (range) & $50(16-152)$ \\
\hline \multicolumn{2}{|l|}{ Type of liver transplant } \\
\hline Deceased donor & $91(60)$ \\
\hline Living donor & $60(40)$ \\
\hline Cytomegalovirus mismatch & $20(13)$ \\
\hline \multicolumn{2}{|l|}{ Immunosuppression treatment } \\
\hline Cyclosporine & $113(75)$ \\
\hline Tacrolimus & $39(26)$ \\
\hline Mycophenolate mofetil & $69(46)$ \\
\hline Azathioprine & $2(1)$ \\
\hline Thymoglobulin & $28(19)$ \\
\hline Basiliximab & $48(32)$ \\
\hline
\end{tabular}

Data presented as $n$ (\%) unless otherwise indicated. MELD Model for Endstage Liver Disease (no additional MELD points for hepatocellular carcinoma); NA Not available

\section{Patients}

The present study was a single-centre, retrospective analysis of all consecutive patients who underwent LT from brain-dead donors or living donors for HCV-related end-stage liver disease from July 2004 to December 2009, yielding a minimum follow-up of at least two years. All patients were followed until May 2011 or until their death. Pretransplant characteristics, including HCV genotype, surgical variables (type of LT, donor age, ischemia times, histological inflammatory grade of explanted liver), and post-transplant information, including cytomegalovirus (CMV) infection (defined as positive CMV polymerase chain reaction in blood and the introduction of antiviral treatment for CMV) and use of antiviral therapy, were collected retrospectively via the Organ Transplant Tracking Registry software (HKS Medical Information Systems, USA), an internal web-based database linked to the electronic medical records of all patients evaluated for a solid organ transplant at the University Health Network (Toronto, Ontario).

\section{Immunosuppression}

Patients were managed according to previously published internal protocols (9). Steroids were given preoperatively (methylprednisolone,
$500 \mathrm{mg}$ intravenously), with a rapid taper to prednisone ( $20 \mathrm{mg}$ daily by mouth) after six days and a more gradual taper over the ensuing three to six months. In living donor LT recipients, antithymocyte globulin (ATG, $1.5 \mathrm{mg} / \mathrm{kg}$ of body weight intravenously and daily for five days) was in routine use until December 2005; basiliximab (20 mg intravenously on postoperative day 0 and 4 ) was introduced from January 2006 onward. Some of the deceased donor liver transplant recipients received induction therapy including basiliximab or ATG for reasons including renal or neurological sparing, mainly to delay the introduction of calcineurin inhibitors. Maintenance immunosuppression consisted of a double- or triple-drug regimen that included tacrolimus or cyclosporine, and prednisone, with or without mycophenolate mofetil (MMF) added for those patients who required cyclosporine or tacrolimus dose reduction. The tacrolimus was monitored by the trough level, and cyclosporine was monitored by the blood concentration level at $2 \mathrm{~h}$ postdose $(\mathrm{C} 2)$.

\section{Laboratory investigations}

The average of values of aspartate aminotransferase (AST [IU/mL]), alanine aminotransferase (ALT $[\mathrm{IU} / \mathrm{mL}])$, and platelet counts $\left(\times 10^{9} / \mathrm{L}\right)$ four to six, and 10 to 12 months post-transplant were evaluated, and described as values at six and 12 months biopsy, respectively.

\section{Histological analysis}

Since July 2004, recipients in the program undergoing LT for hepatitis C are protocolized for liver biopsies at six and 12 months post-LT, and yearly thereafter. Additional biopsies are performed only when clinically indicated. All liver biopsies were read by one of three experienced liver pathologists at the University Health Network, and HCV recurrence was diagnosed based on the typical appearance of mononuclear portal infiltrate with lobular necroinflammation (10). Activity grade and fibrosis stage were scored according to Metavir (11). Mostly, serum HCV RNA-positive patients with histopathological recurrence and Metavir fibrosis stage $\geq 2$ were considered for antiviral therapy.

\section{Statistical analysis}

SPSS version 17.0 (IBM Corporation, USA) was used to analyze the relevant data. Continuous variables were summarized with medians and ranges, whereas categorical variables were presented as proportions. The Student's $t$ test or Fisher's exact test were used for group comparisons. Factors associated with significant fibrosis (SF, fibrosis stage $\geq 2$, according to Metavir score [11]) in protocol liver biopsy at 12 and 24 months were analyzed by univariate logistic regression analysis followed by multivariate analysis with a forward selection procedure. Factors with $\mathrm{P}>0.15$ were removed from the multivariate model. Results are presented as the OR and 95\% CI. Area under the ROC curve (AUROC), sensitivity, specificity, positive predictive value (PPV), and negative predictive value (NPV) were calculated; $\mathrm{P}<0.05$ was considered to be statistically significant.

\section{RESULTS}

From July 2004 to December 2009, 242 consecutive patients underwent LT at the University Health Netowrk for end-stage liver disease related to HCV. Ninety-one patients were excluded from further analysis for the following reasons: biopsy not available or nondiagnostic size/quality $(n=24)$; graft or patient survival shorter than 12 months $(n=21)$; treated biopsy-proven acute cellular rejection ( $n=19)$; biopsyproven chronic rejection $(n=2)$; de novo autoimmune hepatitis $(n=1)$ and biliary complications $(n=14)$; patients undergoing antiviral treatment within six months of LT $(n=10$ [four for fibrosing cholestatic hepatits [FCH], four for SF (fibrosis stage $\geq 2$, as per Metavir [11]; and two for activity grade $\geq 2$ along with fibrosis stage 1 based on the findings of more progression of fibrosis in the patients with significant histological activity early post-LT [5]). The remaining 151 patients without liver problems other than recurrent hepatitis $C$ were analyzed to compare abilities of the liver biopsy and noninvasive parameters to predict the progression of HCV-related fibrosis post-LT by comparing the protocol liver biopsies at six, 12 and 24 months post-LT along with 
TABLE 2

Logistic regression analysis for predicting progression to significant fibrosis at 12 months post-liver transplantation according to factors obtainable at six months

\begin{tabular}{|c|c|c|c|c|c|c|}
\hline \multirow[b]{3}{*}{ Variables } & \multicolumn{2}{|c|}{ Significant fibrosis } & & & & \\
\hline & \multirow{2}{*}{$\begin{array}{c}\text { Positive } \\
(n=17)\end{array}$} & \multirow{2}{*}{$\begin{array}{c}\text { Negative } \\
(n=134)\end{array}$} & \multicolumn{2}{|c|}{ Univariate analysis } & \multicolumn{2}{|c|}{ Multivariate analysis } \\
\hline & & & OR $(95 \% \mathrm{Cl})$ & $\mathbf{P}$ & OR $(95 \% \mathrm{Cl})$ & $\mathbf{P}$ \\
\hline Recipient age, years & $52.1 \pm 6.5$ & $53.8 \pm 6.4$ & $0.96(0.88-1.04)$ & 0.30 & & \\
\hline Male sex, \% & 70 & 82 & $1.99(0.64-6.36)$ & 0.23 & & \\
\hline Caucasian race (versus others), \% & 94 & 75 & $5.54(0.69-42.6)$ & 0.11 & & \\
\hline Body mass index, $\mathrm{kg} / \mathrm{m}^{2}$ & $27.9 \pm 5.1$ & $27.4 \pm 4.4$ & $0.76(0.21-3.11)$ & 0.67 & & \\
\hline HCV genotypes 1 and 4 (versus 2 and 3), \% & 73 & 76 & $1.02(0.91-1.22)$ & 0.89 & & \\
\hline MELD score at liver, points & $18.0 \pm 4.5$ & $17.8 \pm 7.0$ & $0.99(0.91-1.07)$ & 0.79 & & \\
\hline Hepatocellular carcinoma, \% & 53 & 56 & $1.14(0.22-6.11)$ & 0.87 & & \\
\hline Activity grade of explanted liver + & $1.4 \pm 0.51$ & $1.2 \pm 0.37$ & $4.28(0.91-12.8)$ & 0.62 & & \\
\hline Donor age, years & $50.4 \pm 13.5$ & $43.1 \pm 14.6$ & $1.04(0.99-1.07)$ & 0.051 & $1.051(1.007-1.096)$ & 0.023 \\
\hline Cold ischemia time, $\min$ & $324 \pm 236$ & $275 \pm 211$ & 1.001 (0.99-1.003) & 0.39 & & \\
\hline Warm ischemia time, $\min$ & $53.2 \pm 13.6$ & $52.6 \pm 17.3$ & $1.002(0.97-1.03)$ & 0.88 & & \\
\hline Living donor liver transplantation, \% & 35 & 41 & $0.78(0.27-2.45)$ & 0.65 & & \\
\hline Cytomegalovirus infection, \% & 13 & 10 & $1.02(0.81-3.89)$ & 0.23 & & \\
\hline Cyclosporine (versus tacrolimus), \% & 53 & 78 & $0.41(0.15-1.17)$ & 0.10 & & \\
\hline Use of mycophenolate mofetil/azathioprine, \% & 45 & 48 & $0.91(0.44-2.81)$ & 0.76 & & \\
\hline Use of induction therapy, \% & 35 & 52 & $0.51(0.18-1.47)$ & 0.21 & & \\
\hline AST level at six months, IU/mL & $128.4 \pm 58.8$ & $61.5 \pm 39.9$ & $1.023(1.01-1.03)$ & $<0.001$ & 1.025 (1.012-1.033) & $<0.001$ \\
\hline ALT level at six months, IU/mL & $121.6 \pm 69.2$ & $73.4 \pm 43.7$ & $1.014(1.01-1.02)$ & 0.001 & & \\
\hline Platelet count at six months, $\times 10^{9} / \mathrm{L}$ & $194 \pm 92.1$ & $169 \pm 77.3$ & $1.002(0.995-1.01)$ & 0.65 & & \\
\hline Activity grade at six months* & $1.3 \pm 0.85$ & $0.85 \pm 0.75$ & $1.98(1.09-3.57)$ & 0.024 & & \\
\hline Fibrosis stage at six months* & $0.41 \pm 0.51$ & $0.18 \pm 0.37$ & 3.51 (1.20-10.3) & 0.022 & & \\
\hline$\%$ steatosis at six months, $\%$ & $8.24 \pm 10.1$ & $5.2 \pm 10.0$ & $1.02(0.98-1.06)$ & 0.28 & & \\
\hline
\end{tabular}

Data presented as mean \pm SD unless otherwise indicated. *According to Metavir score. ALT Alanine aminotransferase; AST Aspartate aminotransferase; CMV Cytomegalovirus; HCV Hepatitis C virus; MELD Model for End-stage Liver Disease

the demographic information and conventional laboratory parameters (protocol biopsy group). The clinical demographics of the protocol biopsy group are shown in Table 1 .

Among 91 excluded patients, four had abnormalities in liver enzyme levels, then underwent liver biopsy showing recurrent hepatitis $\mathrm{C}$ with SF, and received antiviral therapy within six months of transplant. They had significantly higher AST $(299 \pm 49$ IU/L versus $61 \pm 35 \mathrm{IU} / \mathrm{L} ; \mathrm{P}<0.001)$ and higher ALT $(119 \pm 34 \mathrm{IU} / \mathrm{L}$ versus $58 \pm 41 \mathrm{IU} / \mathrm{L}$; $\mathrm{P}<0.001)$ levels at the time of liver biopsy compared with the 151 patients in the protocol biopsy group.

Factors obtainable at six months and related to SF at 12 months None of the 151 patients included in the protocol biopsy group exhibited SF at six months, and 17 (11.2\%) had SF at 12 months; all underwent antiviral therapy thereafter. The univariate logistic model showed that high AST (by every $1 \mathrm{IU} / \mathrm{L}, \mathrm{OR} 1.023$ [P<0.001]), high histological activity grade and the presence of histological fibrosis (stage 1) at six months biopsy (OR $1.98[\mathrm{P}=0.024]$ and $\mathrm{OR} 3.51[\mathrm{P}=0.022]$, respectively), were significantly associated with progression to $\mathrm{SF}$ at 12 months. Older donor age showed a trend toward predicting progression to SF (per year of donor age, OR $1.04[\mathrm{P}=0.051]$ ). In the multivariate analysis, older donor age (per year of donor age, OR $1.051[\mathrm{P}=0.023]$ ) and high AST at six months biopsy (by every $1 \mathrm{IU} / \mathrm{L}$, OR $1.025[\mathrm{P}<0.001])$ were found to be independent factors associated with progression to SF at 12 months (Table 2).

The diagnostic accuracy (expressed as AUROC) of histological activity grade and fibrosis stage was less favourable than serum AST level at six months biopsy in determining significance of recurrent hepatitis $\mathrm{C}(\mathrm{SF})$ at 12 months. Comparisons of the AUROCs between those features are shown in Figure 1A. The optimal cut-off of the serum AST (highest sensitivity and specificity) at six months biopsy was $82.0 \mathrm{IU} / \mathrm{mL}$ with sensitivity of $88.2 \%$ and specificity of $79.9 \%$, and this correctly identified 107 patients without SF (NPV 98.2\%) and 15 patients with SF (PPV 35.7\%), of the 151 patients, at the 12-month biopsy.

Factors obtainable at 12 months and related to SF at 24 months Of 134 patients who were included in the protocol biopsy group and had a fibrosis score $<2$ at 12 months, six were excluded from subsequent analysis; two had suboptimal biopsy and four underwent antiviral therapy based on high activity (grade 3 ) score in addition to the presence of fibrosis (stage 1) in the liver biopsy at 12 months (5). Of the remaining 128 patients, $25(19.5 \%)$ had SF at 24 months, and all underwent antiviral therapy except one who refused treatment. The univariate analysis showed that high AST at six and 12 months biopsy (OR 1.015 [P=0.012] and OR 1.04 [P<0.001], respectively), high ALT at 12 months biopsy (OR $1.014[\mathrm{P}=0.004])$, high histological high activity grade at six and 12 months biopsy (OR $2.29[\mathrm{P}=0.004]$ and OR $4.69[\mathrm{P}<0.001]$, respectively), and the presence of fibrosis (stage 1) at six and 12 months biopsy (OR $5.43[\mathrm{P}=0.001]$ and $\mathrm{OR} 15.0[\mathrm{P}<0.001]$, respectively), were significantly associated with progression to $\mathrm{SF}$ at 24 months. Older donor age showed a trend toward predicting progression to $\mathrm{SF}$ (per year of donor age, OR $1.032[\mathrm{P}=0.050]$ ). In the multivariate analysis, older donor age (per year of donor age, $\mathrm{OR} 1.050[\mathrm{P}=0.032]$ ), high AST at 12 months biopsy (OR 1.040 [P=0.002]), histological high activity grade at 12 months (OR $2.906[\mathrm{P}=0.031])$, and presence of fibrosis (stage 1 ) at 12 months (OR $5.391[\mathrm{P}=0.010]$ ) were found to be independent factors associated with progression to SF at 24 months (Table 3).

Histological findings at 12 months showed less but still significant ability (expressed as AUROC) than serum AST level at the 12-month biopsy in the prediction of significant recurrent hepatitis $C(S F)$ at 24 months $(\mathrm{P}<0.001$, respectively). Comparisons of the AUROCs between those markers are shown in Figure 1B. The optimal cut-off of serum AST level (highest sensitivity and specificity) at the 12-month biopsy was $52.0 \mathrm{IU} / \mathrm{mL}$ with sensitivity of $80.0 \%$ and specificity of 


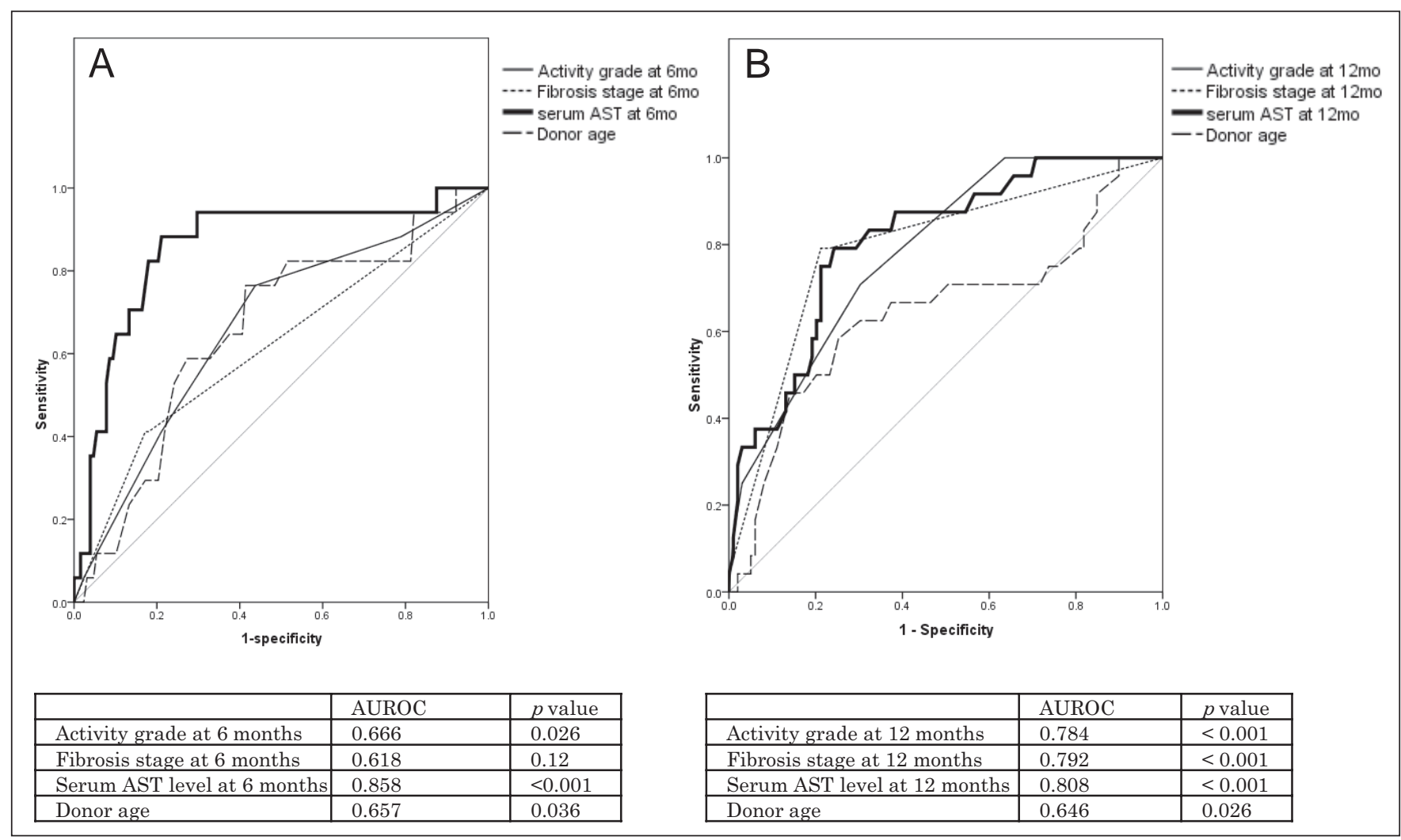

Figure 1) Diagnostic accuracy (expressed as area under ROC curve [AUROC]) of: A Histological activity grade, fibrosis stage and serum aspartate aminotransferase (AST) level at the six-month biopsy, and donor age in progression to significant fibrosis at 12 months; and B Histological activity grade, fibrosis stage and serum AST level at the 12-month biopsy, and donor age in progression to significant fibrosis at 24 months. mo Months

$76.7 \%$, and correctly identified 79 patients without SF (NPV, 94\%) and 20 patients with SF (PPV, 43.5\%), of the 128 patients, at the 24-month biopsy.

\section{DISCUSSION}

The current study compared the protocol liver biopsy early posttransplant (six, 12 and 24 months) with the demographics and routine serum markers in the attempt to identify the indicators of progressive recurrent hepatitis $C$ (fibrosis stage $\geq 2$ ), which usually serves as a trigger for the administration of interferon-based antiviral therapy for recurrent hepatitis $\mathrm{C}$ (12). We found that none of the pretransplant demographic features was associated with the progressive type of $\mathrm{HCV}$ recurrence post-LT within 24 months both on uni- and multivariate analysis, although older donor age showed significant predictability on the progression to SF in two years only on multivariate analysis. Instead, post-transplant AST level was the sole significant parameter that identified those who had SF at one year, on both uni- and multivariate analysis. In addition to AST, histopathological findings (higher-grade activity and presence of fibrosis) of protocol liver biopsies at one year independently showed significant predictability on the progression to SF at two years.

It has been well established that early histological findings of recurrent hepatitis $\mathrm{C}$ strongly predict subsequent progression of graft fibrosis $(5,13,14)$. Sreekumar et al $(15)$ reported that on univariate analysis high histological activity grade in protocol liver biopsy at four months would eventually translate into more advanced stage of fibrosis subsequently. The present analysis showed that the histological activity grade of protocol liver biopsy at six months post-LT showed significant predictability in progressing to SF at 12 and 24 months, again only in univariate analysis. However, our study is still unique because it was conducted to optimize the numbers and timing of protocol liver biopsies by comparing the ability of histological findings with noninvasive factors in association with subsequent progression of fibrosis due to recurrent hepatitis $\mathrm{C}$ from six months to 12 months and from 12 months to 24 months post-LT, on multivariate analysis.

We have previously reported that older donor age ( $>45$ years of age) was independently associated with progressive recurrent hepatitis $C(9)$, consistent with several previous reports (16-20). In the current analysis, older donor age showed significant predictability on progression to SF at both 12 and 24 months in multivariate logistic regression, however, univariate analysis showed only a trend toward progression to SF. High Model for End-stage Liver Disease score pre-LT, high HCV viral load pre and post-LT, high-grade activity in the explant liver, preservation injury and sex have also previously been found to be associated with the progression of HCV recurrence post-LT (15,21-26). However, none of these factors demonstrated independent predictive ability in progression to SF in this current analysis. These differences between the current study and others could be because of the different definition used for the term "significant fibrosis". It is also possible that we were unable to detect these effects because of the relatively short follow-up of our patients and our sample size. We did not evaluate genetic polymorphisms (27-30), morphometric image analysis of collagen in liver biopsy (31), elastography, biochemical markers, fibrogenesis markers, or predictive mathematical models of fibrosis (32), which have also been reported to correlate with fibrosis due to recurrent hepatitis C. Finally, HCV viral loads pre and post-LT were not available in all of our patients, because Ontario's universal health program (Ontario Health Insurance Plan), which is the main health insurance of our study population, did not formally allow costs for serial HCV viral load determination unless the patients were considered for antiviral therapy. Therefore, HCV viral loads pre and post-LT could not be included in the present study.

According to the analysis in our current study, histological findings at six months were not significantly associated with progression to SF at 12 months. On the other hand, serum AST was shown to be the factor most strongly associated with significant $\mathrm{HCV}$ recurrence 
TABLE 3

Logistic regression analysis for predicting progression to significant fibrosis at 24 months post-liver transplantation according to factors obtainable at 12 months

\begin{tabular}{|c|c|c|c|c|c|c|}
\hline \multirow[b]{3}{*}{ Variables } & \multicolumn{2}{|c|}{ Significant fibrosis } & & & & \\
\hline & \multirow{2}{*}{$\begin{array}{l}\text { Positive } \\
(n=25)\end{array}$} & \multirow{2}{*}{$\begin{array}{c}\text { Negative } \\
(n=103)\end{array}$} & \multicolumn{2}{|c|}{ Univariate analysis } & \multicolumn{2}{|c|}{ Multivariate analysis } \\
\hline & & & OR $(95 \% \mathrm{Cl})$ & $\mathbf{P}$ & OR $(95 \% \mathrm{Cl})$ & $\mathbf{P}$ \\
\hline Recipient age, years & $54.8 \pm 6.1$ & $53.5 \pm 6.5$ & $1.03(0.96-1.11)$ & 0.37 & & \\
\hline Male sex, \% & 81 & 84 & $1.33(0.38-4.79)$ & 0.67 & & \\
\hline Caucasian race (versus others), \% & 81 & 78 & $0.73(0.28-1.85)$ & 0.49 & & \\
\hline Body mass index, $\mathrm{kg} / \mathrm{m}^{2}$ & $26.7 \pm 4.4$ & $27.5 \pm 4.3$ & $0.96(0.85-1.08)$ & 0.50 & & \\
\hline Hepatitis C virus genotypes 1 and 4 (versus 2 and 3 ), \% & 75 & 72 & $1.19(0.44-3.84)$ & 0.72 & & \\
\hline MELD score at liver transplantation (by every point) & $18.4 \pm 6.1$ & $17.4 \pm 7.0$ & $0.98(0.92-1.07)$ & 0.67 & & \\
\hline Hepatocellular carcinoma, \% & 56 & 56 & $1.04(0.36-3.08)$ & 0.35 & & \\
\hline Activity grade of explant liver + & $1.13 \pm 0.34$ & $1.14 \pm 0.39$ & $0.78(0.15-3.77)$ & 0.75 & & \\
\hline Donor age, years & $48.1 \pm 15.0$ & $41.4 \pm 14.2$ & $1.032(0.99-1.07)$ & 0.050 & 1.050 (1.004-1.098) & 0.032 \\
\hline Cold ischemia time, $\min$ & $298 \pm 202$ & $268 \pm 213$ & $1.00(0.99-1.00)$ & 0.56 & & \\
\hline Warm ischemia time, min & $50.8 \pm 10.3$ & $52.9 \pm 19.1$ & $0.99(0.97-1.02)$ & 0.61 & & \\
\hline Living donor liver transplantation, \% & 50 & 46 & $0.78(0.31-1.90)$ & 0.54 & & \\
\hline Cytomegalovirus infection, \% & 13 & 12 & $1.01(0.26-3.88)$ & 0.99 & & \\
\hline Cyclosporine (versus tacrolimus), \% & 75 & 77 & $0.43(0.17-1.11)$ & 0.081 & & \\
\hline Use of mycophenolate mofetil/azathioprine, \% & 63 & 48 & $1.20(0.18-1.64)$ & 0.31 & & \\
\hline Use of induction therapy, \% & 63 & 56 & $1.30(0.63-4.87)$ & 0.64 & & \\
\hline AST level at six months, IU/mL & $75.7 \pm 36.1$ & $54.6 \pm 33.1$ & $1.015(1.00-1.03)$ & 0.012 & & \\
\hline AST level at 12 months, IU/mL & $90.8 \pm 46.6$ & $49.1 \pm 25.3$ & $1.04(1.02-1.05)$ & $<0.001$ & $1.040(1.015-1.065)$ & 0.002 \\
\hline ALT level at six months, IU/mL & $81.0 \pm 37.7$ & $69.1 \pm 40.2$ & $1.007(0.99-1.02)$ & 0.21 & & \\
\hline ALT level at 12 months, IU/mL & $96.6 \pm 49.0$ & $63.5 \pm 43.3$ & $1.014(1.01-1.02)$ & 0.004 & & \\
\hline Platelet count at six months, $\times 10^{9} / \mathrm{L}$ & $173 \pm 58.5$ & $168 \pm 74.8$ & $1.001(0.99-1.01)$ & 0.76 & & \\
\hline Platelet count at 12 months, $\times 10^{9} / \mathrm{L}$ & $166 \pm 47.2$ & $168 \pm 78.2$ & $1.00(0.99-1.01)$ & 0.90 & & \\
\hline Activity grade at six months* & $1.20 \pm 0.90$ & $0.72 \pm 0.69$ & $2.29(1.31-4.01)$ & 0.004 & & \\
\hline Activity grade at 12 months* & $1.82 \pm 0.68$ & $1.01 \pm 0.67$ & $4.69(2.30-9.61)$ & $<0.001$ & 2.906 (1.103-7.655) & 0.031 \\
\hline Fibrosis stage at six months* & $0.40 \pm 0.37$ & $0.12 \pm 0.33$ & $5.43(2.00-15.0)$ & 0.001 & & \\
\hline Fibrosis stage at 12 months* & $0.82 \pm 0.41$ & $0.22 \pm 0.41$ & $15.0(4.97-44.1)$ & $<0.001$ & $5.391(1.506-19.30)$ & 0.010 \\
\hline$\%$ Steatosis at six months (per $1 \%$ increase) & $5.6 \pm 6.3$ & $7.2 \pm 9.2$ & $0.98(0.99-1.01)$ & 0.43 & & \\
\hline$\%$ Steatosis at 12 months (per 1\% increase) & $3.1 \pm 5.1$ & $5.8 \pm 12.7$ & $0.96(0.89-1.05)$ & 0.49 & & \\
\hline
\end{tabular}

Data presented as mean \pm SD unless otherwise indicated. *According to Metavir score. ALT Alanine aminotransferase; AST Aspartate aminotransferase; MELD Model for End-stage Liver Disease

within one year. These findings suggest that a protocol biopsy at six months can be omitted in the recipients who have consistently low AST levels. Furthermore, not only serum AST, but histological findings at the 12-month biopsy have strong and independent predictability on the progression to SF at 24 months. Therefore, it can be proposed that recipients with considerable histological findings (high activity grade and presence of fibrosis) at 12 months may benefit from pre-emptive introduction of antiviral therapy. These data also suggest that recipients with minimal findings (low activity grade and absence of fibrosis), especially those with low AST (<57.0 IU/mL, provisionally) at the 12-month biopsy, could avoid the 24-month biopsy.

The difference between the ability of histological findings at six months and 12 months to predict progression of fibrosis is not clear. It could be because earlier biopsies post-LT are more complicated and likely to be influenced by the factors other than hepatitis C, such as postoperative and mechanical effects, although they were not described in the reports of experienced pathologists. Chronic hepatitis C patients with high ALT levels commonly exhibit histological evidence of active inflammation and fibrosis $(33,34)$, even in the posttransplant settings (14). However, it was serum AST, rather than ALT, that had the significant impact on progression of fibrosis in our current study. The reason for this observation is not clear, although the association between AST and graft fibrosis in post-LT settings has also been suggested $(35,36)$. It may be because AST is present in both mitochondria and cytoplasm while ALT is located only in cytoplasm, and thus the recurrent hepatitis $\mathrm{C}$ which is usually more aggressive than in non-LT settings may lead to more AST release with mitochondrial damage.
Further studies to validate our results in other large databases are strongly indicated. Because we excluded the patients with graft or patient survival shorter than 12 months, treated biopsy-proven acute cellular rejection, biopsy-proven chronic rejection and biliary complications, the argument could be made that the selection process in the current study is biased toward those with a relatively uncomplicated post-transplant course attributable to recurrent hepatitis $\mathrm{C}$ and with less aggressive disease. However, most of those excluded patients did not undergo punctual protocol biopsies mainly because of their non-HCV graft problems but instead underwent earlier liver biopsy than scheduled; therefore, we could not include those patients in the analysis.

Our study population includes a sizable number of patients undergoing living donor LT (LDLT) $(n=60[40 \%])$. The cold ischemia time (shorter with LDLT), donor age (younger with LDLT) and use of induction immunosuppression (more in this group), were significantly different than in patients undergoing deceased donor LT (DDLT). However, LDLT did not show significant impact on progression to SF at 12 or 24 months. There was no significant difference between LDLT and DDLT patients, in serum AST or ALT level at six or 12 months biopsy by Student's $t$ test (data not shown).

The present study has several limitations as outlined above, mainly based on its retrospective nature and relatively small number of patients. Currently, we do not have a clear biological explanation for the result acquired from the analysis. However, the current study still has the potential to optimize the timing and reduce the frequency of liver biopsies, and perhaps to optimize the timing of antiviral therapy 
for recurrent hepatitis $\mathrm{C}$ posttransplant, especially with future corroborating evidence.

\section{CONCLUSION}

The current study showed that the protocol liver biopsy performed at six months could be safely eliminated, especially in patients with low AST levels, because of its inability to predict fibrosis progression in another six months. Importantly, no patient with significant fibrosis would have escaped detection at six months if the conclusions of the present study were applied and liver biopsies were performed selectively. However, the protocol biopsy at 12 months still appears to be necessary based on its excellent ability to predict $\mathrm{SF}$ in 12 months' time. In addition, histological activity, the presence or absence of fibrosis, and AST values at the 12-month biopsy (presumably along with donor age) may lead to the decision to defer the protocol biopsy at 24 months, or result in earlier introduction of antiviral therapy, although randomized and prospective trials in this area are highly warranted.

ACKNOWLEDEGMENT: The authors are grateful to Drs Sandra Fischer, Maha Guindi and Oyedele Adeyi for their contribution to the histological examination of the liver biopsies. This study was not funded. The manuscript was not prepared nor funded in any part by a commercial organization. None of the authors have any conflict of interest to declare with regard to the content of this article.

\section{REFERENCES}

1. Adam R, McMaster P, O'Grady JG, et al. Evolution of liver transplantation in Europe: Report of the European Liver Transplant Registry. Liver Transpl 2003;9:1231-43.

2. Berenguer M, Ferrell L, Watson J, et al. HCV-related fibrosis progression following liver transplantation: Increase in recent years. J Hepatol 2000;32:673-84.

3. Berenguer $\mathrm{M}$. What determines the natural history of recurrent hepatitis C after liver transplantation? J Hepatol 2005;42:448-56.

4. Charlton M, Seaberg E, Wiesner R, et al. Predictors of patient and graft survival following liver transplantation for hepatitis C. Hepatology 1998;28:823-30.

5. Gane EJ. The natural history of recurrent hepatitis $\mathrm{C}$ and what influences this. Liver Transpl 2008;14(Suppl 2):S36-44.

6. Saadeh S, Cammell G, Carey WD, Younossi Z, Barnes D, Easley K. The role of liver biopsy in chronic hepatitis C. Hepatology 2001;33:196-200.

7. Cadranel JF, Rufat P, Degos F. Practices of liver biopsy in France: Results of a prospective nationwide survey. For the Group of Epidemiology of the French Association for the Study of the Liver (AFEF). Hepatology 2000;32:477-81.

8. Mells G, Neuberger J. Protocol liver allograft biopsies. Transplantation 2008;85:1686-92.

9. Selzner N, Girgrah N, Lilly L, et al. The difference in the fibrosis progression of recurrent hepatitis $\mathrm{C}$ after live donor liver transplantation versus deceased donor liver transplantation is attributable to the difference in donor age. Liver Transpl 2008;14:1778-86.

10. Adeyi O, Fischer SE, Guindi M. Liver allograft pathology: Approach to interpretation of needle biopsies with clinicopathological correlation. J Clin Pathol 2010;63:47-74.

11. Bedossa P, Poynard T. An algorithm for the grading of activity in chronic hepatitis C. The METAVIR Cooperative Study Group. Hepatology 1996;24:289-93.

12. Practice guidelines for the treatment of hepatitis C: Recommendations from an AISF/SIMIT/SIMAST Expert Opinion Meeting. Dig Liver Dis 2010;42:81-91.

13. Gawrieh S, Papouchado BG, Burgart LJ, Kobayashi S, Charlton MR, Gores GJ. Early hepatic stellate cell activation predicts severe hepatitis $\mathrm{C}$ recurrence after liver transplantation. Liver Transpl 2005;11:1207-13.

14. Russo MW, Firpi RJ, Nelson DR, Schoonhoven R, Shrestha R, Fried MW. Early hepatic stellate cell activation is associated with advanced fibrosis after liver transplantation in recipients with hepatitis C. Liver Transpl 2005;11:1235-41.
15. Sreekumar R, Gonzalez-Koch A, Maor-Kendler Y, et al. Early identification of recipients with progressive histologic recurrence of hepatitis C after liver transplantation. Hepatology 2000;32:1125-30.

16. Berenguer M, Prieto M, San Juan F, et al. Contribution of donor age to the recent decrease in patient survival among HCV-infected liver transplant recipients. Hepatology 2002;36:202-10.

17. Wali M, Harrison RF, Gow PJ, Mutimer D. Advancing donor liver age and rapid fibrosis progression following transplantation for hepatitis C. Gut 2002;51:248-52.

18. Firpi RJ, Abdelmalek MF, Soldevila-Pico C, et al. One-year protocol liver biopsy can stratify fibrosis progression in liver transplant recipients with recurrent hepatitis $\mathrm{C}$ infection. Liver Transpl 2004;10:1240-7.

19. Neumann UP, Berg T, Bahra M, et al. Fibrosis progression after liver transplantation in patients with recurrent hepatitis C. J Hepatol 2004:41:830-6.

20. Rayhill SC, Wu YM, Katz DA, et al. Older donor livers show early severe histological activity, fibrosis, and graft failure after liver transplantation for hepatitis C. Transplantation 2007;84:331-9.

21. Cameron AM, Ghobrial RM, Hiatt JR, et al. Effect of nonviral factors on hepatitis $\mathrm{C}$ recurrence after liver transplantation. Ann Surg 2006;244:563-71.

22. Papatheodoridis GV, Barton SG, Andrew D, et al. Longitudinal variation in hepatitis $\mathrm{C}$ virus (HCV) viraemia and early course of $\mathrm{HCV}$ infection after liver transplantation for HCV cirrhosis: The role of different immunosuppressive regimens. Gut 1999;45:427-34.

23. Ciccorossi P, Maina AM, Oliveri F, et al. Viral load 1 week after liver transplantation, donor age and rejections correlate with the outcome of recurrent hepatitis C. Liver Int 2007;27:612-9.

24. Ghabril M, Dickson RC, Krishna M, et al. Explanted liver inflammatory grade predicts fibrosis progression in hepatitis C recurrence. Liver Transpl 2011;17:685-94.

25. Watt KD, Lyden ER, Gulizia JM, McCashland TM. Recurrent hepatitis $C$ posttransplant: Early preservation injury may predict poor outcome. Liver Transpl 2006;12:134-9.

26. Belli LS, Burroughs AK, Burra P, et al. Liver transplantation for HCV cirrhosis: Improved survival in recent years and increased severity of recurrent disease in female recipients: Results of a long term retrospective study. Liver Transpl 2007;13:733-40.

27. Charlton MR, Thompson A, Veldt BJ, et al. Interleukin-28B polymorphisms are associated with histological recurrence and treatment response following liver transplantation in patients with hepatitis C virus infection. Hepatology 2011;53:317-24.

28. Ben-Ari Z, Pappo O, Druzd T, et al. Role of cytokine gene polymorphism and hepatic transforming growth factor betal expression in recurrent hepatitis $\mathrm{C}$ after liver transplantation. Cytokine 2004;27:7-14.

29. Ben-Ari Z, Tambur AR, Pappo O, et al. Platelet-derived growth factor gene polymorphism in recurrent hepatitis $\mathrm{C}$ infection after liver transplantation. Transplantation 2006;81:392-7.

30. Eid AJ, Brown RA, Paya CV, Razonable RR. Association between toll-like receptor polymorphisms and the outcome of liver transplantation for chronic hepatitis $\mathrm{C}$ virus. Transplantation 2007;84:511-6.

31. Manousou P, Dhillon AP, Isgro G, et al. Digital image analysis of liver collagen predicts clinical outcome of recurrent hepatitis $\mathrm{C}$ virus 1 year after liver transplantation. Liver Transpl 2011;17:178-88.

32. Cross JST, Jothimani D, Heneghan MA, Harrison PM. Non-invasive assessment of fibrosis in liver grafts due to hepatitis C virus recurrence. Clin Transplant 2011;25:345-51.

33. Marcellin P. Hepatitis C: The clinical spectrum of the disease. J Hepatol 1999;31(Suppl 1):9-16.

34. Yeo AE, Ghany M, Conry-Cantilena C, et al. Stability of HCVRNA level and its lack of correlation with disease severity in asymptomatic chronic hepatitis $\mathrm{C}$ virus carriers. J Viral Hepat 2001;8:256-63.

35. Benlloch S, Berenguer M, Prieto M, Rayon JM, Aguilera V, Berenguer J. Prediction of fibrosis in HCV-infected liver transplant recipients with a simple noninvasive index. Liver Transpl 2005;11:456-62.

36. Cross TJ, Calvaruso V, Foxton MR, et al. A simple, noninvasive test for the diagnosis of liver fibrosis in patients with hepatitis C recurrence after liver transplantation. J Viral Hepat 2010;17:640-9. 


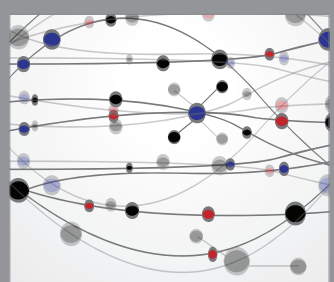

The Scientific World Journal
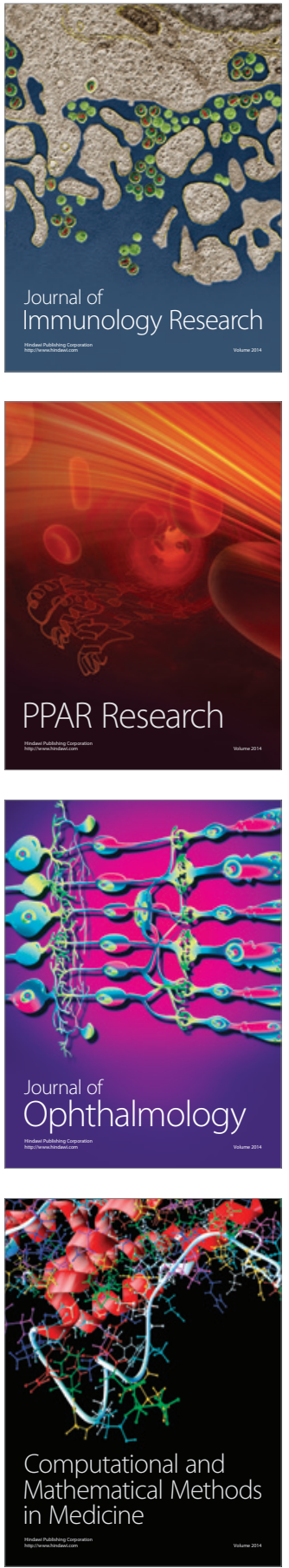

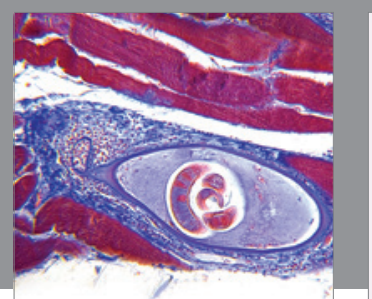

Gastroenterology Research and Practice

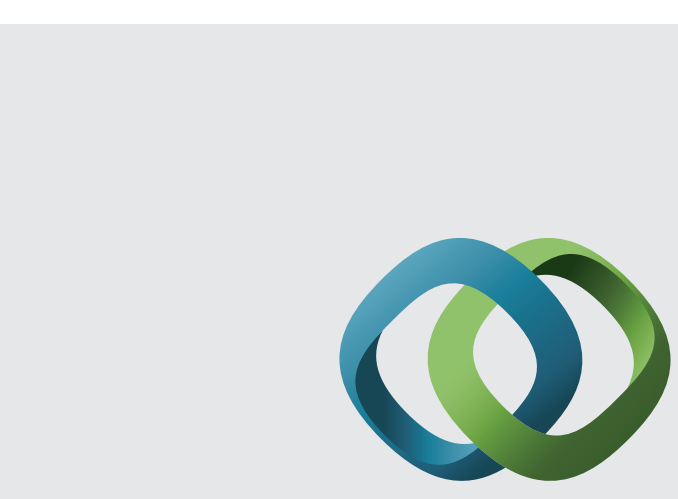

\section{Hindawi}

Submit your manuscripts at

http://www.hindawi.com
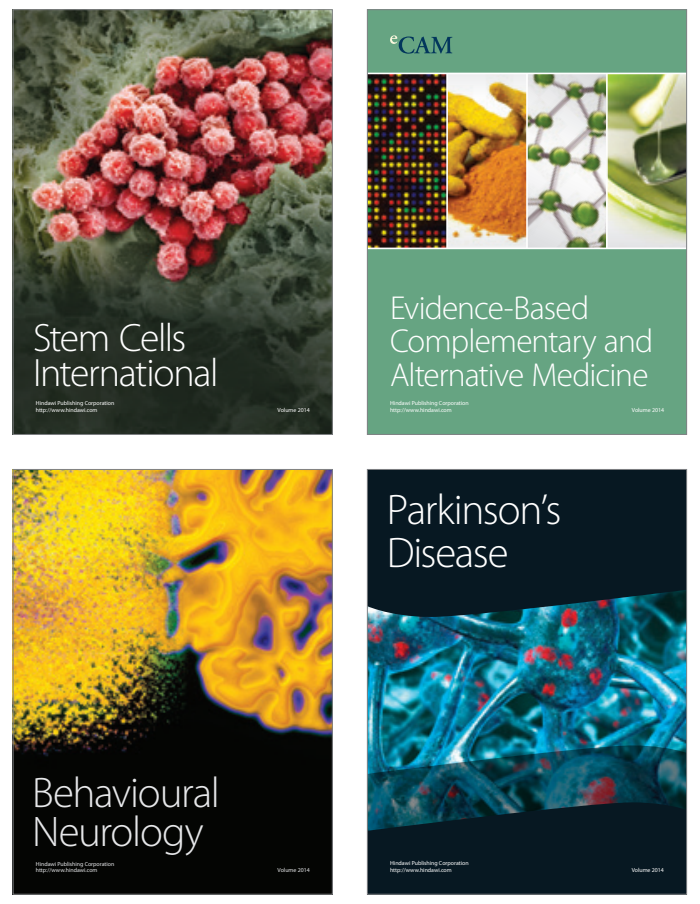
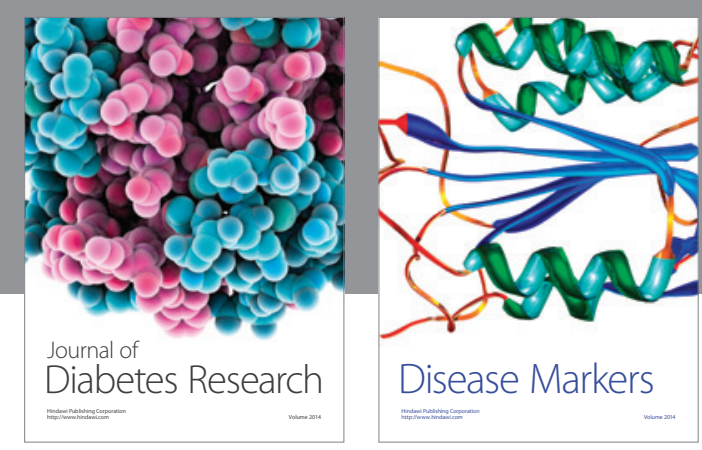

Disease Markers
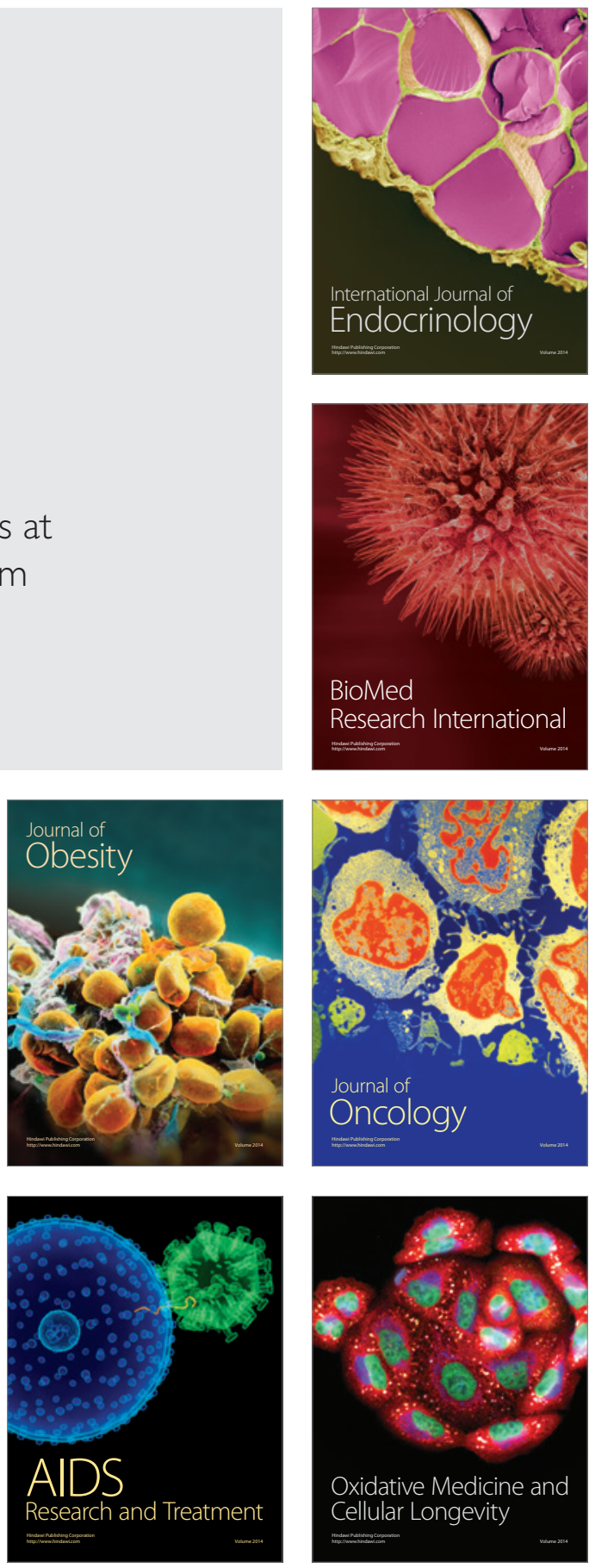